\title{
REVISTA
}

\section{UM OLHAR SOBRE O MERCADO DE CERVEJAS ESPECIAIS CAPIXABA: CARACTERÍSTICAS SOCIODEMOGRÁFICAS DOS EMPREENDEDORES}

\author{
A LOOK AT THE CAPIXABA SPECIAL BEER MARKET: \\ SOCIODEMOGRAPHIC CHARACTERISTICS OF ENTREPRENEURS
}

\author{
${ }^{1}$ Eliza Bottacine Dalvi* \\ ${ }^{2}$ Lucas Marin Bessa \\ ${ }^{3}$ Maíra Maciel Mattos de Oliveira
}

\begin{abstract}
${ }^{1}$ Graduanda do curso de Ciência e Tecnologia de Alimentos do Instituto Federal de Educação, Ciência e
Tecnologia do Espírito Santo- Campus Venda Nova do Imigrante. E-mail: elizadalvi@gmail.com ${ }^{2}$ Professor do Instituto Federal de Educação, Ciência e Tecnologia do Espírito Santo- Campus Venda Nova do Imigrante. E-mail: Lucas.bessa@ifes.edu.br ${ }^{3}$ Professora do Instituto Federal de Educação, Ciência e Tecnologia do Espírito Santo- Campus Venda Nova do Imigrante. E-mail:Maira.oliveira@ifes.edu.br *Autor de correspondência
\end{abstract}

Artigo submetido em 11/07/2020, aceito em 10/03/2021 e publicado em 15/04/2021.

Resumo: Na produção de cerveja nacional evidenciam-se as regiões Sul e Sudeste como as maiores produtoras, destacando-se, na região sudeste, o Espírito Santo (ES) por seu mercado em expansão. Contudo, apesar do crescimento registrado nos últimos anos, poucos são os estudos que descrevem características específicas do segmento de cervejas especiais. Objetivou-se com o presente estudo identificar o perfil dos empreendedores do mercado de cervejas especiais do estado do ES segundo características sociodemográficas. Utilizou-se um questionário estruturado, com questões abertas e fechadas, elaborado por meio de um formulário eletrônico e aplicado em abril de 2018, visando caracterizar os empreendedores quanto à questões como: gênero, faixa etária, formação profissional, fonte de renda, tempo de atuação no setor e participação em cursos na área cervejeira e qual o motivo que levou-o a investir no ramo de cervejas especiais. Tenda em vista o objetivo da presente pesquisa em elaborar o perfil do empreendedor de cervejas especiais capixaba, tem-se que o mesmo pode ser caracterizado como do sexo masculino, casado, entre 32 e 38 anos, tem ensino superior, maioria formado na área de ciências humanas, já atuou em sua área de formação, atua de 2 a 4 anos no setor de cervejas, está em processo de formação continuada, tem renda de mais de 9 salários mínimos e possui outras fontes de renda, sendo a de empresário de outro ramo em sua maioria. Por fim, quanto a motivação para entrar no segmento, todos afirmaram ter sido por oportunidade de negócio.

Palavras-chave: Empreendedorismo; mercado cervejeiro; cervejas artesanais; Espírito Santo.

Abstract: In the national beer production, the South and Southeast regions are highlighted as the largest producers, with Espírito Santo (ES) standing out in the southeastern region for its expanding market. However, despite the growth recorded in recent years, there are few studies that describe specific characteristics of the specialty beer segment. This study aims to identify the profile of entrepreneurs in the specialty beer market in the state of ES according to sociodemographic 
characteristics. A structured questionnaire was used, with open and closed questions, elaborated through an electronic form and applied in April 2018, aiming to characterize the entrepreneurs regarding issues such as: gender, age group, professional training, income source, time of performance in the sector and participation in courses in the beer area and what was the reason that led them to invest in the specialty beer business. Bearing in mind the objective of the present research in elaborating the profile of the entrepreneur of special beers from Espírito Santo, it can be described as male, married, between 32 and 38 years old, with higher education, most graduated in the area of human sciences, has worked in his training area, works for 2 to 4 years in the beer sector, is in the process of continuing education, has an income of more than 9 minimum wages and has other sources of income, being that of an entrepreneur from another mostly branch. Finally, regarding the motivation to enter the segment, all said it was due to a business opportunity.

Keywords: Entrepreneurship; beer market; craft beers; Espírito Santo.

\section{INTRODUÇÃO}

A história do mercado cervejeiro brasileiro se inicia no período denominado Brasil Colônia (MEGA, 2011), se estendendo até os dias de hoje representando um dos setores que mais cresce na economia nacional. Atualmente, o Brasil é destaque como o terceiro maior produtor de cerveja e um dos grandes consumidores mundiais (VASCONCELOS, 2017). Na produção de cerveja nacional, de acordo com dados do Ministério da Agricultura Pecuária e Abastecimento (MAPA), evidenciam-se as regiões Sul e Sudeste como as maiores produtoras.

Dentre os estados da região sudeste, destaca-se o Espírito Santo com seu mercado em expansão, acompanhado pelo turismo de perfil gastronômico. No estado do Espírito Santo no ano de 2017 foram contabilizadas 11 cervejarias, não entrando nesse balanço as cervejarias ciganas, que são empresas legalmente constituídas, mas que não possuem uma estrutura produtiva própria, dado que realizam as suas produções em cervejarias terceirizadas devidamente registradas no MAPA (MÜLLER \& MARCUSSO, 2017).

Apesar da grande expansão registrada nos últimos anos, poucos são os estudos que descrevem características específicas do segmento de cervejas especiais, bem como suas particularidades. Além disso, quando analisado os dados da pesquisa Global Entrepreneurship Monitor - GEM (GEM BRASIL, 2019) sobre o perfil dos empreendedores do Brasil e do mundo, observa-se que boa parte dos números utiliza o mercado como um todo para análise, não focando detalhes de segmentos específicos.

Devido à necessidade de se conhecer as características dos mercados produtores e de seus empreendedores, objetivou-se com o presente estudo identificar o perfil dos empreendedores do mercado de cervejas especiais do estado do Espírito Santo segundo características sociodemográficas, bem como identificar informações relevantes que auxiliem a compreender características e demandas desse mercado, fazendo um paralelo com a pesquisa do GEM (GEM BRASIL, 2019), que aborda o empreendedorismo no Brasil e no mundo.

\section{REFERENCIAL TEÓRICO}

No Brasil, a história cervejeira inicia-se em 1808 com a vinda da família real portuguesa para a colônia. Isso aconteceu devido à abertura dos portos às nações amigas de Portugal, sendo a Inglaterra a primeira a trazer a bebida para o país (MEGA, 2011). Em relação à produção da cerveja no Brasil, não se sabe ao certo quando se deu início, data-se a segunda metade do século XIX como o começo da criação das primeiras cervejas 
industrializadas no

país (VASCONCELOS, 2017)

Até 1850 têm-se notícias de algumas cervejarias no Rio de Janeiro, São Paulo e regiões da imigração alemã no Rio Grande do Sul. A produção da bebida no sul do país era mais comum em casa, sendo comercializadas em vendas-cervejeiras como atividades secundárias (SANTOS, 2004). O setor cervejeiro no Brasil foi criado em 1853 e possui uma extensa e importante cadeia que movimenta desde o agronegócio ao pequeno varejo no país, incluindo os mercados de embalagens, logística, maquinário e construção civil. De acordo com dados da Associação Brasileira da Indústria Cervejeira (Cervbrasil), no anuário de 2016, o mercado cervejeiro contribuiu com $1,6 \%$ do PIB nacional, faturando cerca de 77 bilhões de reais por ano, representando $14 \%$ da indústria de transformação nacional, e expressiva geração de empregos diretos ou indiretos em torno de 2,2 milhões de vagas (CERVBRASIL, 2016).

O Brasil é o terceiro maior produtor de cerveja e um dos grandes consumidores mundiais, sendo fabricados 13,8 bilhões de litros por ano, o que coloca o país no ranking global atrás apenas da China e dos Estados Unidos (VASCONCELOS, 2017). A produção nacional apresenta uma tendência crescente nos últimos 30 anos, sendo que o MAPA lista as regiões sul e sudeste como os maiores produtores de cerveja do Brasil. De acordo com o anuário da cerveja no Brasil publicado pelo mesmo órgão, o número de cervejarias legalmente instaladas no país chegou a 679 estabelecimentos em 2017, sendo o Rio Grande do Sul o estado com maior número de cervejarias (142), seguido por São Paulo (124) e Minas Gerais (87) (MÜLLER \& MARCUSSO, 2017).

Atualmente, o setor cervejeiro brasileiro vive uma grande expansão de microcervejarias, visto que, de acordo com a Associação Brasileira de Microcervejarias (Abracerva), já existem no país, aproximadamente, 420 estabelecimentos do tipo. Juntos, os mesmos respondem por $1 \%$ do volume consumido no país (VASCONCELOS, 2017).

No Espírito Santo, observa-se uma forte prevalência de cervejarias produtoras de cervejas especiais, tendo grande impacto pelo turismo de perfil gastronômico. Além disso, Brew Pubs e cervejarias abrem suas portas todos dias para receber diretamente os consumidores, principalmente no interior do estado, propagando e dando forma à cultura cervejeira capixaba.

Segundo informações da Associação dos Cervejeiros Artesanais do Espírito Santo (ACERVA-ES), a produção de cerveja artesanal no estado é, atualmente, de, aproximadamente, $40 \mathrm{mil}$ litros por mês, valor esse que tende a aumentar, representativamente, com a aprovação da lei que cria nova regra tributária para as cervejarias artesanais capixabas, com a redução do Imposto sobre a Circulação de Mercadorias e Serviços (ICMS) sancionada em 2017, de acordo com o Governo do Estado, o que incentiva o investimento no setor (FOLHA VITÓRIA, 2017).

De acordo com os dados do Instituto Brasileiro de Geografia e Estatística IBGE (2019), o estado do Espírito Santo tem mais de quatro milhões de pessoas, com rendimento mensal em torno de hum mil e quatrocentos reais e cerca de $61,8 \%$ da sua população em cargos de trabalho formais. Quando analisado o índice de desenvolvimento humano, o mesmo Instituto declara o valor de 0,74 como Índice de Desenvolvimento Humano - IDH, que avalia questões ligadas à educação, saúde e renda, próximo dos 0,76 do estado do Rio de Janeiro e acima dos 0,73 registrados no estado de Minas Gerais. Além disso, de acordo com pesquisa realizada pelo Instituto Jones dos Santos Neves - IJSN (2018), o Produto Interno Bruto do Estado acumulou um resultado no ano de 2017 de $1,7 \%$, muito acima dos $1 \%$ alcançado pelo Brasil 
quando analisado o dado do País como um tudo.

Analisando-se a pesquisa do GEM (GEM BRASIL, 2019), a maioria dos empreendimentos estabelecidos no Brasil são geridos por homens, o que indica uma diferença de $13 \%$ entre os gêneros. Nesse tipo de empreendimento existe predominância de indivíduos com idades entre 35 e 44 anos $(26,5 \%)$ e de 45 a 54 anos $(27,5 \%)$. Quando se analisam os empreendimentos iniciais, não existe diferença entre homens e mulheres. Para empreendimentos iniciais, a faixa etária predominante é de 25 aos 34 anos (27,7\%), seguida pelos 35 a 44 anos $(27,1 \%)$.

Considerando os níveis de escolaridade dos empreendedores brasileiros segundo o GEM (GEM BRASIL, 2019), nota-se que a maior parte possui ensino médio completo, sendo mais frequente para negócios novos $(46,2 \%)$ e estabelecidos $(32,7 \%)$. Uma análise mais crítica indica que em torno da metade dos empreendedores brasileiros estabelecidos $(57,5 \%)$ e notável número dos iniciais $(38,2 \%)$ não concluiu o nível básico de ensino, composto pelos ciclos fundamental e médio, implicando diretamente em maiores desafios impostos para a sobrevivência dos empreendimentos. A baixa representatividade geral de empreendedores com maior escolaridade pode ser explicada pelas amplas possibilidades de inserção no mercado de trabalho.

No que se refere à renda familiar dos empreendedores no Brasil, 26,2\% dos estabelecidos estão em famílias com renda de três até seis salários mínimos. A menor participação é a com renda familiar superior a seis salários mínimos $(12,7 \%)$ dos estabelecidos. Para novos estabelecimentos a maior parte dos empreendedores $(26,8 \%)$ possui renda familiar entre três até seis salários mínimos, sendo a menor faixa composta por famílias com renda superior a seis salários mínimos $(11,1 \%)$, de acordo com o GEM (GEM BRASIL, 2019).
A obtenção de dados sociodemográficos de empreendedores apresenta-se como ferramenta relevante para caracterizar um mercado, seu perfil, lacunas e perspectivas futuras, além de possibilitar a comparação dos dados encontrados com a pesquisa GEM (GEM BRASIL, 2019), fator este que motivou a pesquisa em questão.

\section{PROCESSOS METODOLÓGICOS}

Para o desenvolvimento da presente pesquisa utilizou-se um questionário estruturado, com questões abertas e fechadas, elaborado por meio de um formulário eletrônico e aplicado em abril de 2018, visando caracterizar os empreendedores do ramo de cervejas especiais quanto à questões sociodemográficas, como: gênero, faixa etária, formação profissional, fonte de renda, tempo de atuação no setor e participação em cursos na área cervejeira e qual o motivo que levou-o a investir no ramo de cervejas especiais.

Quanto ao gênero, o intuito foi avaliar a quantidade de investidores do sexo masculino e feminino e, na faixa etária, buscou-se mensurar a média de idade dos investidores. No que se refere a formação profissional, objetivou-se avaliar se os mesmos são formados em áreas de alimentos e afins e/ou se dedicam apenas a atividade de cervejas especiais como uma forma de diversificação dos seus investimentos. Ainda sobre a questão, questionou-se quanto se utilizam de outra fonte de renda ou dependem apenas do faturamento da cervejaria. $O$ tempo de atuação no setor foi levado em consideração visando conhecer um pouco da evolução do empreendedor no ramo de cervejas especiais e sua experiência. Sobre a participação em cursos de formação continuada, o propósito foi avaliar se há interesse em capacitação entre os empreendedores do segmento e em quais áreas. Por fim, questionou-se sobre o motivo que levou o empreendedor a 
investir no ramo de cervejas especiais com a finalidade de mensurar os motivos para realizar tal investimento.

A aplicação do questionário deu-se com os dados disponibilizados em consulta à Associação de Cervejeiros Artesanais do Estado do Espírito Santo (ACERVA-ES). Através dos mesmos, selecionou-se os empreendedores do setor que possuem empreendimentos que atendem aos requisitos legais de comercialização, sendo estes: cervejarias, Brew Pubs e produção "cigana". Posteriormente, realizou-se contato telefônico com os participantes visando a divulgação da pesquisa e a disponibilização do link para acesso ao questionário. $\mathrm{O}$ instrumento foi aplicado em abril de dois mil e dezoito e contou com a participação de 13 empreendedores. Enfatiza-se que em 2017 haviam 11 estabelecimentos com registro no MAPA para comercialização de cervejas especiais no Espírito Santo. Apesar de ainda não ter sido divulgado oficialmente pelo MAPA, observa-se a presença de novos registros no mercado.

Após a coleta dos dados disponibilizados na pesquisa, realizou-se a análise descritiva dos mesmos.

\section{RESULTADOS E DISCUSSÃO}

No que diz respeito ao sexo dos empreendedores, observou-se que, dos 13 participantes, 11 eram do sexo masculino e 2 do sexo feminino. Destaca-se que a inserção feminina no desenvolvimento de empreendimentos mostrou-se crescente nos últimos anos, fato este também observado na área de cervejas especiais. De acordo com Komar (2018), a inserção do público feminino no mercado de cervejas especiais está em crescimento acelerado, destacando-se a criação e produção nas cervejarias, a atuação como sommelières, professoras, juízas de concursos, administradoras de cervejarias e pesquisadoras. A autora também cita que a procura por cursos e especializações é reflexo da intenção de empreender na área.
Os respondentes declararam ser, em sua maioria, casados (10), com apenas 3 declarando-se solteiros, o que coincide com a pesquisa GEM (GRECO, 2016). A faixa etária, por sua vez, indica a prevalência de empreendedores apresentando de 32 a 38 anos (5). Os demais participantes se enquadraram nas faixas etárias de: 25 a 31 anos (3), 38 a 44 anos (2), 45 a 51 anos (1), 52 a 58 anos (2).

O grau de escolaridade relatado indica que a maioria dos empreendedores capixabas da área de cervejas especiais possui ensino superior (8) ou PósGraduação (4), com apenas 1 participante da pesquisa indicado possuir ensino médio completo e formação em curso técnico, tornando este público diferente da caracterização realizada pela pesquisa GEM (2019), que afirma que a maior parte dos empreendedores têm ensino superior incompleto. A formação na área de Ciências Humanas (5) destacou-se, seguida pela área de Engenharias (2). Os demais empreendedores relataram possuir formação nas áreas de Ciência Agrárias (1), Ciências Biológicas (1), Ciências Exatas e da Terra (1), Ciências Sociais Aplicadas (1), Gastronomia (1) e Turismo (1). Esse comportamento de respostas demonstra que a inserção no mercado de cervejas especiais não necessariamente ocorre indo ao encontro da área de formação do empreendedor. Dos 13 empreendedores participantes da pesquisa, 9 relataram já ter atuado em sua área de formação, 2 ainda atuam e 2 nunca atuaram.

O tempo de atuação no setor cervejeiro demonstra que a maioria dos empreendedores (5) está na área há um período que varia de 2 a 4 anos, seguindo pelo período de 4 a 6 anos (4) e pelo período que indica menos de 2 anos da área (4).

Todos os empreendedores iniciaram o negócio por oportunidade, ou seja, abriram observando a oportunidade como investimento. Dentre os motivos que levaram os empreendedores a investir no 
setor cervejeiro, destacam-se: a demanda crescente do mercado (citado 8 vezes), a paixão pela área de cervejas especiais (citado 5 vezes), o aumento da fonte de renda (citado 2 vezes) e, citados uma vez, a vontade de transformar o hobby em negócio, o interesse pela área, os estudos recentes sobre cervejas especiais e a oportunidade de criação de um empreendimento familiar.

O treinamento constante foi indicado pela maioria dos participantes, 10 disseram já ter realizado cursos na área. Entre os cursos citados, destacam-se, em ordem decrescente de apresentação: Sommelier de cervejas, Tecnologia cervejeira (avançada e básica, bem como aplicada à produção artesanal), Microbiologia da cerveja e Análise Sensorial, demonstrando que os empreendedores estão em um processo de formação continuada, característica valorizada para o crescimento.

Dos entrevistados, 10 possuem outra fonte de renda e 3 dependem apenas do setor cervejeiro. Quanto às outras fontes de renda apresentadas, a maioria se declarou empresário(a) (7), seguido pelas ocupações: funcionário(a) de empresa privada (2), autônomo(a) (1), e servidor público (1). Dois declararam não possuir outra fonte de renda. A distribuição dos entrevistados nas faixas de renda apresentadas, por sua vez, foi de: menos de 3 salários mínimos (2), de 3 a 6 salários mínimos (2), de 6 a 9 salários mínimos (2) e mais de 9 salários mínimos (7), valores superiores às médias apontadas pela pesquisa GEM (GEM BRASIL, 2019)

\section{CONCLUSÕES}

Após pesquisa bibliográfica realizada e a aplicação do formulário, observou-se que os investidores do ramo de cervejas artesanais do estado do Espírito Santo apresentam características específicas que o diferenciam da pesquisa GEM (GEM BRASIL, 2019) em alguns pontos, como a faixa de renda, elevada quando comparada com a pesquisa em questão, e nível de escolaridade, sendo muitos empreendedores com titulação acima da média encontrada, fator este que pode ter sido determinante para a resposta dada por muitos entrevistados que afirmaram ter entrado no segmento como oportunidade de investimento. Quanto às questões de investidores do sexo masculino como prevalência, observou-se alinhamento com a pesquisa GEM (GEM BRASIL, 2019).

Tendo em vista o objetivo da presente pesquisa em elaborar o perfil do empreendedor de cervejas especiais capixaba, tem-se que o mesmo pode ser caracterizado, em sua maioria, como do sexo masculino, casado, entre 32 e 38 anos, tem ensino superior, maioria formado na área de ciências humanas, já atuou em sua área de formação, atua de 2 a 4 anos no setor de cervejas, está em processo de formação continuada, tem renda de mais de 9 salários mínimos e possui outras fontes de renda, sendo, também, a de empresário de outro segmento em sua maioria.

Por fim, espera-se que, a partir de pesquisas como essa e novas bases de dados, o segmento de cervejas artesanais cresça, ainda mais, e crie novas oportunidades de renda, emprego e negócio para os atuais e novos empreendedores.

\section{REFERÊNCIAS}

CERVBRASIL. Anuário 2016.

CERVBRASIL, 2016. Disponível em: http://www.cervbrasil.org.br/novo_site/anu ario/. Acesso em: 17 ago 2020.

\section{FOLHA VITÓRIA. Alíquota de ICMS para cervejarias artesanais é reduzida no Espírito Santo. FOLHA VITÓRIA,} 2017. Disponível em: http://m.folhavitoria. com.br/economia/noticia/2017/06/aliquotade-icms-para-cervejarias-artesanais-ereduzida-no-espirito-santo.html. Acesso em: 12 ago 2020. 
GLOBAL ENTREPRENEURSHIP

MONITOR. Empreendedorismo no

Brasil - Relatório Executivo: 2019.

Curitiba: IBQP, 2019. 30 p. Disponível em http://ibqp.org.br/PDF\%20GEM/Relatório $\%$ 20Executivo\%20Empreendedorismo\%20 no\%20Brasil\%202019.pdf . Acesso em: 18 agos 2020.

IBGE. Consulta de dados no portal.

IBGE, 2019. Disponível em:

https://www.ibge.gov.br/cidades-e-

estados/es.html. Acesso em: 17 ago 2020.

IJSN. PIB capixaba cresce $1,7 \%$ no acumulado do ano de 2017. IJSN, 2018. Disponível em: http://www.ijsn.es.gov.br /artigos/5030-pib-trimestral-4-trimestre-de2017. Acesso em: 12 ago2020.

KOMAR, A. P. Cerveja não é coisa de mulher? Cerveja de Todos os Jeitos. Edição 63, ano 6, maio 2018.

MEGA, J. F.; NEVES, E.; ANDRADE, C. J. de. A produção de cerveja no Brasil.

Revista Citino, v. 1, n. 1, p. 34-42, 2011.

MÜLLER, C. V.; MARCUSSO, E. F. Anuário da cerveja no Brasil. Disponível em: http://www.agricultura.gov.br /assuntos/inspecao/produtos-vegetal/pastapublicacoes-DIPOV/anuario-da-cervejano-brasil-mapa.pdf. Acesso em: 17 ago 2020.

SANTOS, S. P. Os primórdios da cerveja no Brasil. 2. Ed. Cotia: Ateliê Editorial, 2004.

VASCONCELOS, Y. Inovações cervejeiras. Revista Pesquisa Fapesp, Edição 251, Janeiro 2017. Disponível em: http://revistapesquisa.fapesp.br/2017/01/09 /inovacoes-cervejeiras/. Acesso em: 12 ago 2020. 